\title{
Anatomicosurgical References for Endoscopic Localization of Sphenopalatine Foramen: A Cadaveric Study
}

\author{
${ }^{1}$ Anjali Aggarwal, ${ }^{2}$ Tulika Gupta, ${ }^{3}$ Daisy Sahni, ${ }^{4}$ Ashok Gupta
}

\begin{abstract}
Introduction: In patients with posterior epistaxis, generally the source of bleeding is branches of sphenopalatine artery (SPA), which enter the nasal cavity through the sphenopalatine foramen (SPF). Cases of intractable massive bleeding may require endonasal endoscopic occlusion of these vessels.
\end{abstract}

Materials and methods: A total of 32 hemisections of formalinfixed cadaveric heads were used. The anatomic variations of SPF, its distance from anatomical landmarks, and angle of elevation of endoscope were studied so as to facilitate accurate localization of the foramen and endoscopic arterial ligation.

Results: The SPF was generally single; however, multiple exits in the form of accessory foramina were found in $36.75 \%$ hemisections. The transition of superior and middle meatuses was the most common location of SPF, followed by the superior meatus, and middle meatus was the least common site. The accessory foramina were commonly present in the superior meatus. Ethmoid crest was distinctly visible in all but two cases. In majority of the cases, the SPF was located within a range of 55 to $65 \mathrm{~mm}$ from the anterior nasal spine (ANS); 60 to $70 \mathrm{~mm}$ from piriform aperture, 50 to $60 \mathrm{~mm}$ from limen nasi, 20.1 to $25 \mathrm{~mm}$ vertically above the floor of nasal cavity, and 8 to $15 \mathrm{~mm}$ from the inferior turbinate (IT). The angulation of SPF from the floor of nasal cavity was 20 to $30^{\circ}$.

Conclusion: Exploration of lateral nasal wall (LNW) up to middle meatus would minimize the risk of missing any arterial branch, and the data of distance from the anatomical references would assist in more precise localization of SPF during endoscopic ligation or cauterization of the branches of the SPA.

Keywords: Endoscopy, Posterior epistaxis, Sphenopalatine artery, Sphenopalatine foramen.

How to cite this article: Aggarwal A, Gupta T, Sahni D, Gupta A. Anatomicosurgical References for Endoscopic Localization of Sphenopalatine Foramen: A Cadaveric Study. Clin Rhinol An Int J 2016;9(3):109-114.

\footnotetext{
${ }^{1,2}$ Assistant Professor, ${ }^{3}$ Professor and Head, ${ }^{4}$ Professor

${ }^{1-3}$ Department of Anatomy, Postgraduate Institute of Medical Education and Research, Chandigarh, India

${ }^{4}$ Department of Otolaryngology, Head and Neck Surgery Postgraduate Institute of Medical Education and Research Chandigarh, India

Corresponding Author: Anjali Aggarwal, Assistant Professor Department of Anatomy, Postgraduate Institute of Medical Education and Research, Chandigarh, India, Phone: +911722755203, e-mail: anjli_doc@yahoo.co
}

\section{Source of funding: Nil}

Conflict of interest: None

\section{INTRODUCTION}

Epistaxis is one of the commonest clinical presentations that the otolaryngologists come across. Most cases of epistaxis, particularly if the source of bleeding is an anteriorly located vessel, are easy to manage. Bleeding from posteriorly located vessel though less common is difficult to control. ${ }^{1}$ Several authors have concluded that the lateral nasal wall (LNW) is the primary site of refractory posterior epistaxis. Posterior nasal cavity, particularly mucosa of LNW and septum, is perfused mainly by branches of sphenopalatine artery (SPA). ${ }^{2}$ Sphenopalatine artery enters the nasal cavity through sphenopalatine foramen (SPF). Cases of intractable massive bleeding refractory to conservative management require surgical interruption of arterial blood supply of nasal mucosa. Endonasal endoscopic occlusion of SPA is considered a safer option. ${ }^{3}$

Though the results of endoscopic SPA ligation are encouraging, failure in localization and endoscopic ligation of SPA has been encountered in 2 to $20 \%$ of cases, particularly by beginners early in their endoscopic experience. ${ }^{4}$ Key to successful identification of the bleeding vessel and further therapeutic intervention is accuracy in topographic localization of SPF. Surgical approaches rely on landmarks that can assist in localizing SPF. Efforts have been made in the past to search reliable location landmarks. Anterior nasal spine (ANS), horizontal plate of palatine bone, and bony crista ethmoidalis are few such examples. ${ }^{1,4,5}$ Large variations with regard to the measurements of distance of SPF from the landmarks have been reported in the literature. ${ }^{5}$ The current study was planned to provide a detailed account of the variations of the SPF and to determine the location of SPF by taking measurements from anteriorly and posteriorly located intranasal landmarks relevant to endoscopic localization of SPA and the best angle for endoscope elevation to reach the SPF.

\section{MATERIALS AND METHODS}

The study was conducted on 32 sagitally sectioned formaldehyde-preserved adult cadaveric head hemisections 
(16 right and 16 left). Corps with history of nasal trauma or any endonasal surgery were excluded from the study. Vertical incision was given in the mucosa of LNW and extending upward from the posterior end of the inferior turbinate (IT) to the sphenoid sinus. Mucosa flap was elevated until SPF was indentified. Photodocumentation of all cases was done.

\section{Anatomical Observations}

Lateral nasal walls of hemisections were studied under magnoscope (magnification of lens $2 \times$ ) and following anatomical features were recorded:

- Presence of well-defined ethmoid crest of perpendicular plate of palatine bone.

- Localization of SPF in relation to ethmoid crest. Sphenopalatine foramen was considered located in the superior meatus if the lower margin of foramen lies above the level of ethmoid crest; at the transition of superior and middle meatus if the crest lies in line of middle of the foramen; at the middle meatus if the upper margin of foramen lies below the level of ethmoid crest.

- Localization of accessory foramen if any.

\section{Anatomical Measurements}

- Distances of inferior margin of SPF and accessory foramen were measured from the following anatomical landmarks (Fig. 1):

- Anterior nasal spine (ANS-SPF)

- Plane of piriform aperture (PA-SPF)

- Limen nasi (LN-SPF)

- Floor of nasal cavity (vertical distance) (NF-SPF)

- Posterior end of IT (IT-SPF)

- Angle of foramen from floor of nasal cavity: For measuring the angle, a transparency was placed on

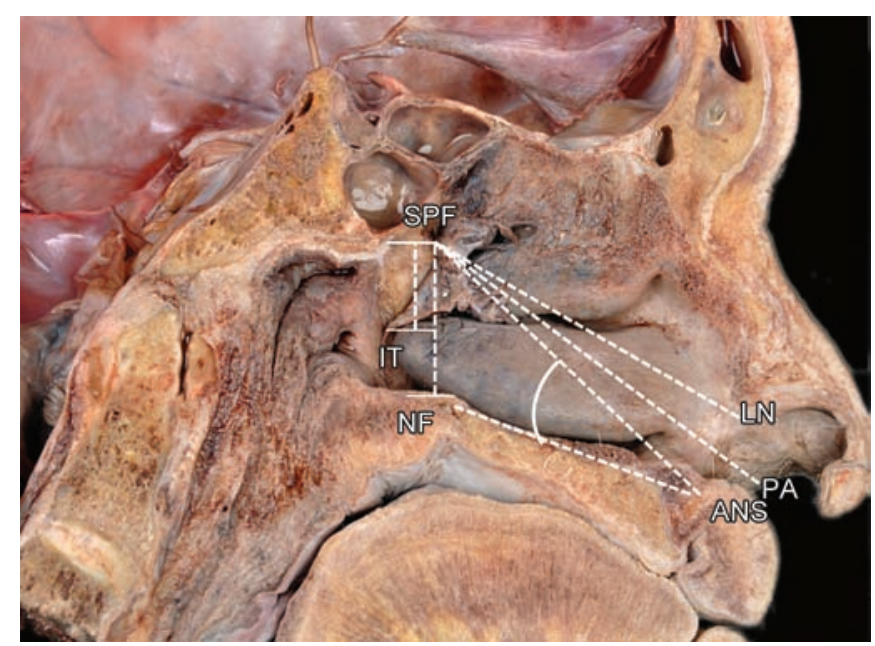

Fig. 1: Hemisection of head and neck showing measurements. (SPF: Sphenopalatine foramen; ANS: Anterior nasal spine; PA: Piriform aperture; LN: Limen nasi; NF: Nasal cavity floor; IT: Inferior turbinate) the section. Two lines, one extending from the ANS along the floor of nasal cavity and second from the ANS to inferior margin of SPF, were drawn on the transparency. Angle between these two lines was measured. This angle indicated the angle of elevation of endoscope introduced through the PA.

For linear and angular measurements, digital caliper of precision $0.02 \mathrm{~mm}$ (Mitutoyo Co., Kawasaki, Japan) and protractor respectively, were used.

\section{RESULTS}

\section{Anatomical Observations}

Ethmoid crest of perpendicular plate of palatine bone was distinctly visible in 30 (93.75\%) LNWs. In one hemisection, part of LNW was hypoplastic, represented by cartilaginous tissue, and ethmoid crest was not visible, and in another specimen, ethmoid crest was not appreciable (Figs 2A to D). Twenty (62.5\%) LNWs presented solitary opening of SPF. More than one foramen was seen in 12 (37.5\%) LNWs, double in 10 (31.25\%), and triple in 2 (6.25\%). In cases with multiple foramina, the largest foramen was considered as the main SPF, and smaller was taken as the accessory foramen.

\section{Localization of the Foramen}

The main SPF was lying above the line of ethmoid crest, implying position in the superior meatus in 8 (25\%) cases; at the level of ethmoid crest indicating the transition of superior and middle meatus in 17 cases (53.12\%); and in 5 cases $(15.62 \%)$, SPF was present below the ethmoid crest indicating position in the middle meatus. Two cases in which ethmoid crest was not visible, SPF was located above the line of attachment of middle meatus, suggesting its position in the superior meatus. Thus, in 10 cases (31.25\%), the SPF was positioned in the superior meatus. In cases with double SPF, the accessory foramen was situated in the superior meatus in eight (25\%) cases and middle meatus in two (6.25\%) cases. In one of the cases with triple foramina, one accessory foramen was lying above and the other below the main SPF in the middle meatus. In the second case of triple SPF, both accessory foramina were located in the superior meatus.

\section{Distance from Intranasal Landmarks}

The distances of SPF from the landmarks are given in Table 1; they varied widely. We categorized the measurements into groups. For anteriorly located references, the groups were $<50 \mathrm{~mm} ; 50.1$ to $55 \mathrm{~mm} ; 55.1$ to $60 \mathrm{~mm} ; 60.1$ to $65 \mathrm{~mm}$, and $>65 \mathrm{~mm}$ (Graph 1). From the ANS, the SPF was lying in the range of 50 to $55 \mathrm{~mm}$ in $12.5 \%$ cases; 55.1 to $60 \mathrm{~mm}$ in $21.9 \%$ cases; 60.1 to $65 \mathrm{~mm}$ in $50 \%$ cases, 


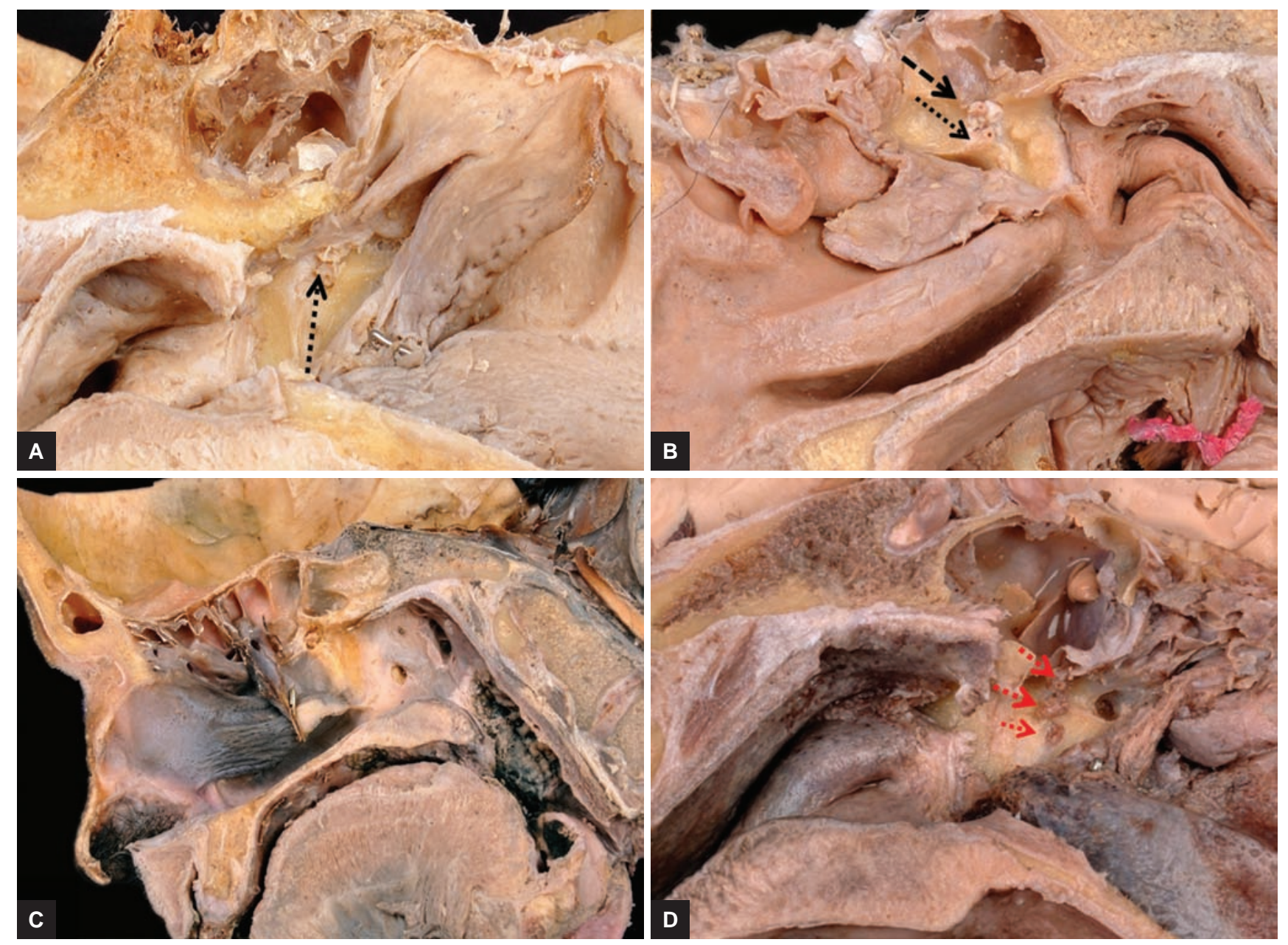

Figs 2A to D: Dissected LNW showing variations of number and position of SPF: (A) SPF lying in the line of ethmoid crest (SPF at the transition of superior and middle meatus); (B) Double SPF - the main SPF and the accessory foramen lying in the superior meatus; (C) LNW is hypoplastic, ethmoid crest is not visible, and SPF is located in the superior meatus; and (D) Triple SPF - the main SPF at the transition of superior and middle meatuses, one accessory in the superior and the other in the middle meatus

Table 1: Summary of the results

\begin{tabular}{llllllll}
\hline Parameters & Range & Mean \pm SD & SE & Median & Mode & 95\% confidence interval Skewness \\
\hline ANS-SPF $(\mathrm{mm})$ & $50.00-68.42$ & $60.69 \pm 4.72$ & 0.83 & 61.00 & 64.92 & $58.96-62.35$ & $-0.407(\mathrm{SE}=0.414)$ \\
PA-SPF $(\mathrm{mm})$ & $49.00-70.14$ & $61.90 \pm 5.57$ & 0.97 & 62.50 & 67 & $59.86-63.82$ & $-0.685(\mathrm{SE}=0.414)$ \\
Limen nasi-SPF $(\mathrm{mm})$ & $45.00-60.00$ & $54.26 \pm 3.23$ & 0.57 & 54.00 & 54.21 & $52.99-55.32$ & $-0.131(\mathrm{SE}=0.414)$ \\
Nasal floor-SPF $(\mathrm{mm})$ & $18.67-26$ & $22.16 \pm 2.00$ & 0.51 & 22.6 & 23 & $21.59-23.22$ & $-0.730(\mathrm{SE}=0.414)$ \\
IT-SPF $(\mathrm{mm})$ & $8.32-20.00$ & $13.14 \pm 2.55$ & 0.46 & 13 & 15 & $12.15-14.03$ & $-0.112(\mathrm{SE}=0.414)$ \\
Angle of endoscope insertion & $14.00^{\circ}-34.00^{\circ}$ & $24.94^{\circ} \pm 3.35$ & 0.59 & $26^{\circ}$ & 26 & $23.73^{\circ}-26.14^{\circ}$ & $-0.793(\mathrm{SE}=0.414)$ \\
\hline
\end{tabular}

and 65 to $68.42 \mathrm{~mm}$ in the remaining $15.6 \%$ cases. With piriform aperture taken as a reference, the SPF was lying in the range of 50 to $55 \mathrm{~mm}$ in $12.5 \%$ cases; 55.1 to $60 \mathrm{~mm}$ in $15.6 \%$; 60.1 to $65 \mathrm{~mm}$ in $34.4 \%$; 65.1 to $70 \mathrm{~mm}$ in $37.5 \%$ cases. From another anteriorly located landmark, the limen nasi, the measurements were 45 to $50 \mathrm{~mm}$ in $3.1 \%$; 50.1 to $55 \mathrm{~mm}$ in $62.5 \%$; 55.1 to $60 \mathrm{~mm}$ in $31.3 \%$; 60.1 to 65 $\mathrm{mm}$ in $3.1 \%$ cases. From these observations, we evaluated the range in which majority cases were falling. In $71.9 \%$ cases, ANS-SPF distance was lying in the range of 55.1 to $65 \mathrm{~mm}$, and PA-SPF distance was lying in the range of 60.1 to $70 \mathrm{~mm}$. In $93.8 \%$, the SPF was lying in the range of
50.1 to $60 \mathrm{~mm}$ from the limen nasi. (Frequency distribution is shown in the bar diagram in Graph 1.)

Average perpendicular distance of SPF from the floor of nasal cavity was $22.16 \mathrm{~mm} \pm 2$ (18.67 to $26 \mathrm{~mm})$. This distance was 18.67 to $20 \mathrm{~mm}$ in $6(18.75 \%)$ cases; 20.1 to $25 \mathrm{~mm}$ in $24(75 \%)$ cases; and 25.1 to $26 \mathrm{~mm}$ in $2(6.25 \%)$ cases (Graph 2). From the posterior end of IT, the distance range was 8.32 to $10 \mathrm{~mm}$ in $18.75 \%$ cases; 10.1 to $15 \mathrm{~mm}$ in $21(65.25 \%)$ cases; 15.1 to $20 \mathrm{~mm}$ in $15.62 \%$ cases. (Distribution of data shown in scatter plot in Graph 3.)

The angle between the floor of nasal cavity and the line joining ANS and SPF varied from 14 to $34^{\circ}$. The 


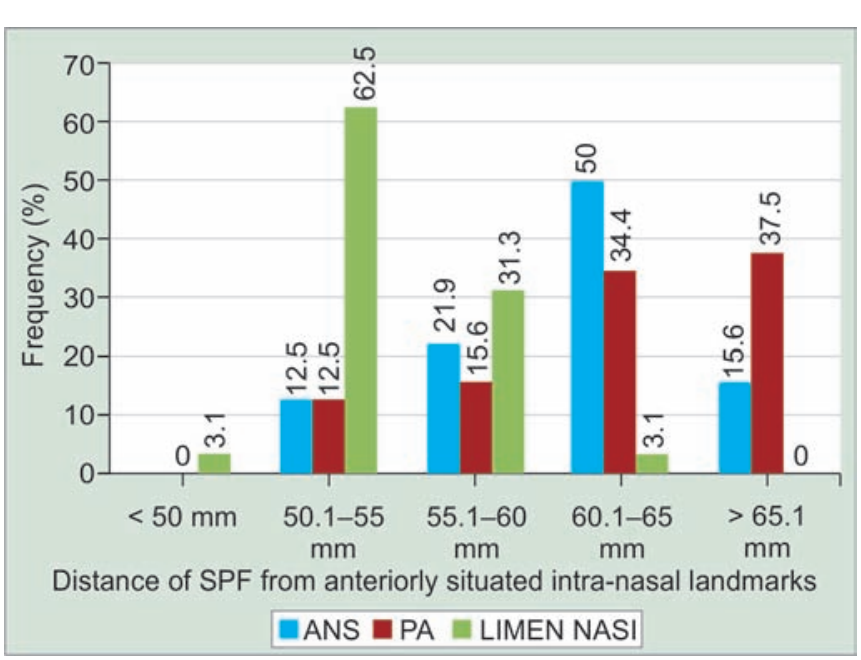

Graph 1: Frequency of five groups of each parameter (SPFANS; SPF-PA; SPF-LN)

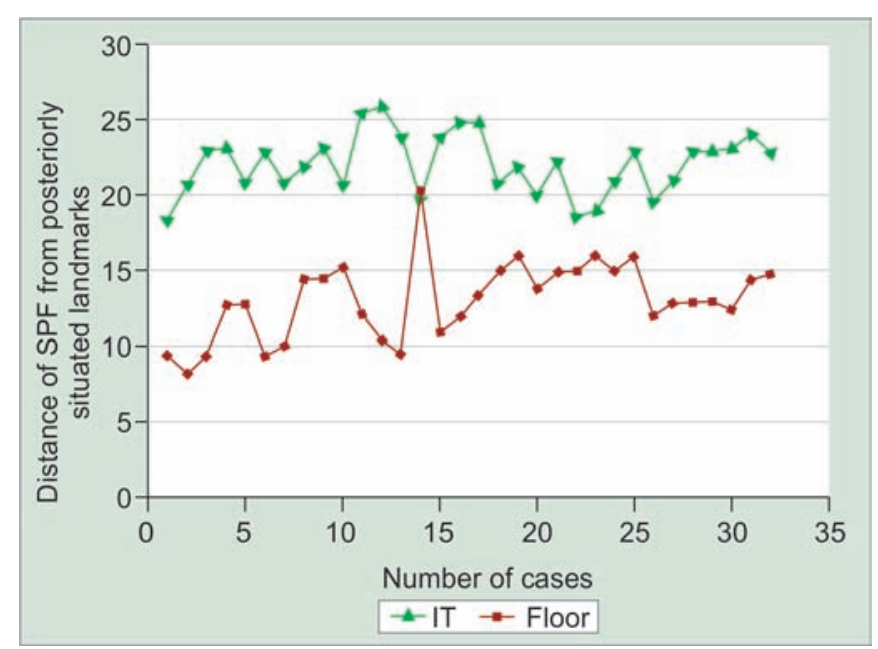

Graph 3: Scatter plot showing distribution of data of distance of SPF from floor of nasal cavity and inferior turbinate

angle was $<20^{\circ}$ in $3.1 \%, 20.1^{\circ}$ to $25^{\circ}$ in $31.3 \%, 25.1^{\circ}$ to $30^{\circ}$ in $62.5 \%$ cases, $30.1^{\circ}$ to $34^{\circ}$ in $3.1 \%$ cases. In majority of the cases $(93.8 \%)$, the angle was lying between $20 .^{\circ}$ and $30^{\circ}$ (Graph 2).

\section{Statistical Analysis}

A test $(p>0.05)$ and visual inspection of histogram and $\mathrm{Q}-\mathrm{Q}$ plot showed that the distances of ANS, PA, IT, and nasal floor were approximately normally distributed with a skewness of 0.407 [standard error (SE) $=0.414], 0.685(\mathrm{SE}=0.414), .112(\mathrm{SE}=0.414)$, and 0.730 $(\mathrm{SE}=0.414)$ respectively, whereas the distance of limen nasi $(\mathrm{p}<0.05)$ from SPF was significantly skewed with a skewness of $-0.131(\mathrm{SE}=0.414)$. Similarly, the angle was also found to be significantly skewed ( $p<0.01)$ with a skewness of -0.793 (SE $=0.414$ ).

Bland-Altman plots showed that measurements obtained from piriform aperture and ANS were interchangeable as no significant $(p>0.05)$ differences were

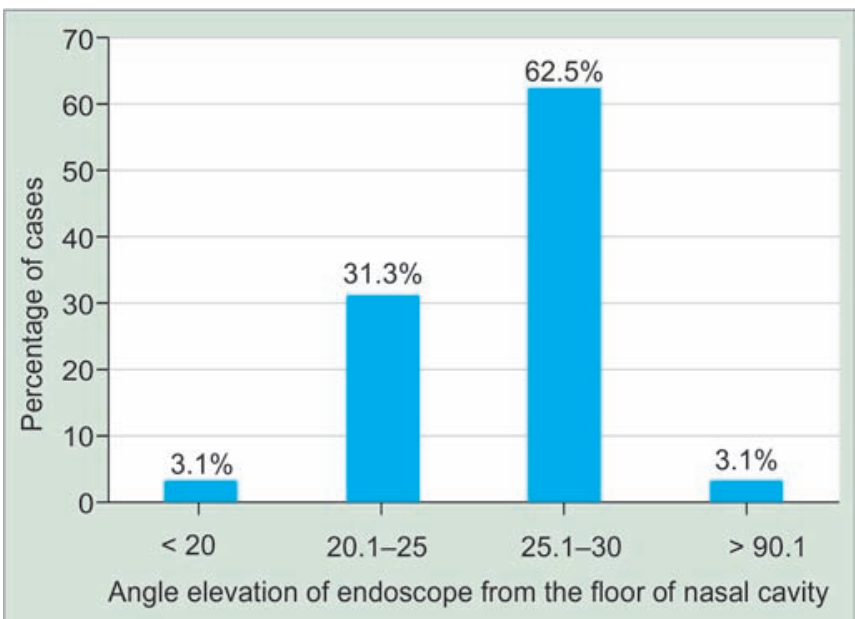

Graph 2: Frequency of angle of elevation of endoscope from the floor of nasal cavity

observed in the mean values of two measurements. Most of the values were between \pm 1.96 standard deviation (SD).

\section{DISCUSSION}

Nasal mucosa receives blood supply mainly from ophthalmic branch of internal carotid artery and maxillary branch of external carotid artery. In pterygopalatine fossa, the maxillary artery gives off SPA, which passes through SPF, the only communication between the fossa and nasal cavity. In order to reach the SPA, it is ideal to know the variations and location of the SPF.

Bolger et $\mathrm{al}^{1}$ in 1999 described a landmark in LNW, which leads to SPF, the crista ethmoidale of perpendicular plate of palatine bone to which the middle turbinate joins. Wareing and Padgham ${ }^{6}$ proposed a classification of localization of SPF utilizing its relation with the ethmoid crest. Pádua and Voegels ${ }^{4}$ supported the recommendations of Bolger et $\mathrm{al}^{1}$ by finding it in $100 \%$ of the specimens. This classification was followed by many researchers to describe the location of SPF. According to Budrovich and Seatti, ${ }^{7}$ this could be well recognizable in hemisection of head; however, for endoscopically locating the SPF, the ethmoid crest is not well marked enough in every skull and not easy to locate. In two of our specimens, ethmoid crest was not discernible at all. In one case, part of LNW was hypoplastic (represented by sheet of cartilaginous tissue), accounting for the absence of ethmoid crest. We reviewed the literature and did not come across any such case. Though the percentage of the absence of ethmoid crest is small, this fact cannot be ignored and thus reliability of this reference in every case is questionable.

With regard to number of SPF varying from one to three, our results were in accordance with published literature. ${ }^{8,9}$ Presence of single foramen was the commonest observation. The incidence of multiple foramina recorded in our specimens (36.75\%) was close to $38.5 \%$ recorded by 
Nikolic. ${ }^{8}$ Scanavini et al ${ }^{9}$ found multiple foramina in $13 \%$ of the cases. Double foramina have been seen in 10 to $12 \%$ of the cases. ${ }^{6,8-10}$ Percentage of double foramina recorded in our study (31.5\%) was close to the one presented by Nikolic. ${ }^{8}$ Occurrence of triple foramina is relatively less common. Nikolic ${ }^{8}$ detected triple orifice in 39 cases $(5.5 \%)$ of large samples studied, and Scanavini et al ${ }^{9}$ found in only one of the specimens (1.9\%). Despite the small sample size of our study, we found triple orifice in two cases (6.25\%).

Positional variability of the SPF is not unusual. The SPF has been found in LNW in any position from recess above superior turbinate to middle meatus. ${ }^{4,6,9,11,12}$ We observed the main SPF most frequently at the transition of superior and middle meatuses $(53.12 \%)$. The foramen was at the level of superior meatus in $31.25 \%$ and middle meatus in $15.62 \%$ specimens. Our data were quite close to the one given by Wareing and Padgham ${ }^{6}$ collected from bone specimens ( $56 \%$ at the transition; $35 \%$ in superior meatus; $9 \%$ in middle meatus). This is further supported by work done by Pádua and Voegels ${ }^{4}$ who found the foramen at the transition in majority of specimens examined (86.9\%) and in the remaining $13.1 \%$ cases in the superior meatus. Midilli et al ${ }^{12}$ found at the transition in $80 \%$ and in the superior meatus in $20 \%$ LNW. Contrary to these observations, some other studies found SPF most frequently in the superior meatus. Lee et $\mathrm{al}^{11}$ noted at this site in $90 \%$ specimens and Scanavini et $\mathrm{al}^{9}$ in $81.5 \%$. Sphenopalatine foramen has also been spotted in the middle meatus, with recorded incidence of 1.9 to $9 \% .{ }^{6,9,10}$ We found SPF in relatively higher number (15.6\%). Fourth though least common position is superior to the attachment of superior turbinate by Lee et $\mathrm{al}^{11}$ in $10 \%$ specimens.

The accessory foramina are generally found anterior to the main SPF. Most of the researchers have found them in the middle meatus. In our samples, they were detected most commonly in the superior meatus and in a few cases at the transition of superior and middle meatuses. Thus, in view of getting best results and exposing all potential accessory foramina, we recommend the exploration extending from superior turbinate to the attachment of superior turbinate to middle meatus.

This variation in the number and position of SPF may be due to variation in the entry of SPA into the nasal cavity. Lee et $\mathrm{al}^{11}$ found two to four branches arising from SPA in pterygopalatine fossa, and each branch entered independently into the nasal cavity. This number corresponds to variation of arterial branches exiting through accessory foramina resulting in multiple foramina. This alteration in the input of the arterial nasal irrigation is relevant while managing severe epistaxis through ligation of SPA. Numerical variation is considered to be the major factor for failure of complete ligation of SPA branches. Schwartzbauer et $\mathrm{al}^{2}$ in 8 out of 19 dissections (42\%) found SPA emerging into the nasal cavity through the accessory foramen situated posterior to SPF and recommended that dissection should be continued posterior.

The second part of our study consisted of measurement of SPF from anatomical landmarks to get closest estimate of SPF from the references. The most certain way of reaching SPF is to know its exact location, and therefore, establishment of a constant reference point is of great importance for successful endoscopic ligation or cauterization of SPA. In the past, attempts have been made to identify satisfactory references for locating the foramen. The ANS is one of the most commonly used references. Reviewing the literature reveals that the foramen lies between 51 and $81 \mathrm{~mm}$ from the ANS, and the average distance varies from 59 to $66 \mathrm{~mm} .{ }^{4,9,13}$ The values are based on dry skull or cadaveric dissection. Our results (average $60.69 \pm 4.72$, range 50 to 68.42 ) closely matched with those of Scanavini et $\mathrm{al}^{9}$ and Hadoura et al. ${ }^{13}$ Data in the literature as well as our study show wide range of these measurements. Therefore, we evaluated the range of majority of the cases. In majority of the cases $(72 \%)$, the infraorbital foramen was situated in the narrow range of 55.1to $65 \mathrm{~mm}$ distance from ANS (Table 2).

Table 2: Comparison with the published literature

\begin{tabular}{|c|c|c|c|c|c|c|}
\hline & $\begin{array}{l}\text { ANS-SPF } \\
(\mathrm{mm})\end{array}$ & $P A-S P F(m m)$ & $\begin{array}{l}\text { Limen nasi- } \\
\text { SPF }(\mathrm{mm})\end{array}$ & $\begin{array}{l}\text { Nasal floor-SPF } \\
(\mathrm{mm})\end{array}$ & $I T-S P F(m m)$ & $\begin{array}{l}\text { Angle from floor } \\
\text { of nasal cavity }\end{array}$ \\
\hline $\begin{array}{l}\text { Scanavini et } \mathrm{al}^{9} \\
\text { ( } \mathrm{n}=12 \text { cadavers })\end{array}$ & $\begin{array}{l}58.98 \pm 4.36 \\
(51.50-68.35)\end{array}$ & - & - & - & - & $\begin{array}{l}26.20^{\circ} \pm 5.64^{\circ} \\
\left(20^{\circ}-32^{\circ}\right)\end{array}$ \\
\hline $\begin{array}{l}\text { Hadoura et al }{ }^{13} \\
\mathrm{n}=28\end{array}$ & $\begin{array}{l}59 \pm 3.978 \\
(50-69)\end{array}$ & $\begin{array}{l}48.48 \pm 3.51 \\
(40.5-57.5)\end{array}$ & - & - & - & $\begin{array}{l}22.56^{\circ} \pm 3.214^{\circ} \\
\left(14^{\circ}-32^{\circ}\right)\end{array}$ \\
\hline $\begin{array}{l}\text { Prades et al } \\
\text { ( } \mathrm{n}=12 \text { skulls) }\end{array}$ & - & - & - & $18.27(15.09-20.87)$ & $13(9-14.85)$ & - \\
\hline $\begin{array}{l}\text { Lee et al }{ }^{11}(n=50 \\
\text { hemisections })\end{array}$ & - & $59.4 \pm 4.2$ & $49.1 \pm 3.7$ & - & - & - \\
\hline $\begin{array}{l}\text { Pádua and Voegels }{ }^{4} \\
\text { ( } \mathrm{n}=122 \text { cadavers) }\end{array}$ & $66 \pm 5.350-81$ & - & - & - & - & - \\
\hline $\begin{array}{l}\text { Current (2015) ( } n=32 \\
\text { hemisections) }\end{array}$ & $\begin{array}{l}60.70 \pm 4.80 \\
(50-68.42)\end{array}$ & $\begin{array}{l}61.90 \pm 5.57 \\
(48.6-70.14)\end{array}$ & $\begin{array}{l}54.26 \pm 3.17 \\
(45-60)\end{array}$ & $\begin{array}{l}22.37 \pm 2.28 \\
(18.67-26)\end{array}$ & $\begin{array}{l}13.14 \pm 2.55 \\
(8.32-20)\end{array}$ & $\begin{array}{l}24.94^{\circ} \pm 3.35^{\circ} \\
\left(14^{\circ}-36^{\circ}\right)\end{array}$ \\
\hline
\end{tabular}


Plane of PA is another landmark, which may guide surgeons as to how far they should introduce the endoscope to reach the foramen. Average observed in our study $(61.9 \pm 5.57)$ was close to the value recorded by Lee et $\mathrm{al}^{11}(59.4 \pm 4.2 \mathrm{~mm})$. The distance measured by Hadoura et $\mathrm{al}^{13}$ showed lower value. Our results revealed that in majority $(72 \%)$ of the cases, the SPF was located in the narrow range of 60 to $70 \mathrm{~mm}$.

Limen nasi is another though less studied reference. Lee et $\mathrm{al}^{11}$ recorded average distance of $49.1 \pm 1.97 \mathrm{~mm}$ from it. Our results showed higher value for this distance. However, in $93.8 \%$, the SPF was lying in the range of 50.1 to $60 \mathrm{~mm}$. Comparative assessment of anterior anatomical references showed least variation in the distance range from limen nasi, since in more than $90 \%$ of the cases, the SPF was located 50.1 to $60 \mathrm{~mm}$ from limen nasi. Out of all anteriorly located landmarks, the distance of SPF from limen nasi showed the least variation. Best reference appears to be limen nasi.

Prades et $\mathrm{al}^{5}$ found inferior border of SPF situated at an average $18.27 \mathrm{~mm}(15.09-20.67 \mathrm{~mm})$ above the horizontal plate of palatine bone. Our results for same measurement were on the higher side $(22.19 \pm 1.97 \mathrm{~mm})$. In $75 \%$ of the midsections studied by us, the SPF was lying within the range of 20.1 to $25 \mathrm{~mm}$ from the floor of the nasal cavity. Prades et al ${ }^{5}$ worked on bony skull, whereas we studied on cadaveric specimens, which is more close to real-life situations. Another posteriorly situated reference that can assist in localization of foramen is horizontal lamina of IT. The mean $(13.14 \mathrm{~mm})$ recorded in our study was very close to the one recorded by Prades et $\mathrm{al}^{5}$ (average $13.04 \mathrm{~mm}$ ). In $84 \%$ of the cases, SPF was located in the range of 18.32 to $25 \mathrm{~mm}$ from IT.

To minimize the number of attempts and enhance the chances of achieving correct localization of SPF, besides knowing the relationship to surrounding landmarks, it is essential to have an idea of the optimum angle of endoscope elevation. The average recorded in previous work varied between 22 and $26^{\circ}$ and range between 14 and $32^{\circ} .9,13$ Our results were falling in this range. In $93.8 \%$ of the cases, the SPF was lying at an angulation between 20 and $30^{\circ}$.

\section{CONCLUSION}

The present study has provided detailed information concerning the variations and localization of SPF. Highlight of our study is comparative assessment of anatomical references and provision of distance range with high likelihood of reaching SPF. This aspect has not been addressed before. These distance references for the use of the endoscope in endonasal ligation or cauterization of the branches of the sphenopalatine would assist in more precise localization and minimizing the risk of missing any arterial branch. More work needs to be done particularly in the patients to validate our observations. To expose all potential accessory foramina, it is advisable to explore both superior and middle meatuses before finishing the surgery.

\section{ACKNOWLEDGMENT}

The authors wish to thank all who have donated their body to the Department of Anatomy, Mr Pradeep Sing for photography, and Mrs Shallu Jagii for statistical analysis.

\section{REFERENCES}

1. Bolger WE, Borgie RC, Melder P. The role of the crista ethmoidalis in endoscopic sphenopalatine artery ligation. Am J Rhinol 1999 Mar-Apr;13(2):81-86.

2. Schwartzbauer HR, Shete M, Tami TA. Endoscopic anatomy of the sphenopalatine and posterior nasal arteries: implications for the endoscopic management of epistaxis. Am J Rhinol 2003 Jan-Feb;17(1):63-66.

3. Voegels RL, Thomé DC, Iturralde PPV, Butugan. Endoscopic ligature of the sphenopalatine artery for severe posterior nasal haemorrhage. Otolaryngol Head Neck Surg 1999;13: 137-140.

4. Pádua FGM, Voegels RL. Surgical implication of the endoscopic sphenopalatine forame region's anatomy. Int Arch Otolaryngol 2007;11:469.

5. Prades JM, Asanau A, Timoshenko AP, Faye MB, Martin CH. Surgical anatomy of the sphenopalatine foramen and its arterial content. Surg Radiol Anat 2008 Oct;30(7):583-587.

6. Wareing MJ, Padgham ND. Osteologic classification of the spheno-palatine forame. Laryngoscope 1998 Jan;108(1 Pt 1): 125-127.

7. Budrovich R, Saetti R. Microscopic and endoscopic ligature of the sphenopalatine artery. Laryngoscope 1992 Dec;102(12 Pt 1):1391-1394.

8. Nikolic V. Variations lê trou sphéno-palatin. Acta Anat (Basel) 1967;68:189-198.

9. Scanavini AB, Navarro JA, Megale SR, Lima RS, AnselmoLima WT. Morphometric evaluation of the sphenopalatine foramen for endonasal surgery. Rhinology 2010 Dec;48(4): 441-445.

10. Bagatella F. Vidian nerve surgery revisited. Laryngoscope 1986 Feb;96(2):194-197.

11. Lee HY, Kim H, Kim S, Son EJ, Kim JW, Cho NH, Kim KS, Lee JG, Chung IH, Yoon JH. Surgical anatomy of the sphenopalatine artery in lateral nasal wall. Laryngoscope 2002 Oct;112(10):1813-1818.

12. Midilli R, Orhan M, Saylam CY, Akylidiz S, Gode S, Karci B. Anatomic variations of sphenopalatine artery and minimally invasive surgical cauterization procedure. Am J Rhinol Allergy 2009 Dec;23:e38-e41.

13. Hadoura L, Douglas C, McGarry GW, Young D. Mapping surgical coordinates of the sphenopalatine foramen: surgical navigation study. J Laryngol Otol 2009 Jul;123(7):742-745. 